张辉, 莫康乐, 李婷, 曾晨军, 陈求稳, 许承双, 汤新武, 吴炎. 鄱阳湖水利枢纽工程建设对草鱼江湖洄游潜在的影响. 生态学报, 2022, 42 (2) : 600-610.

Zhang H, Mo K L, Li T, Zeng C J, Chen Q W, Xu C S, Tang X W, Wu Y.The potential influence of the Poyang Lake Hydraulic Project construction on riverlake migration of grass carp. Acta Ecologica Sinica, 2022,42(2):600-610.

\title{
鄱阳湖水利枢纽工程建设对草鱼江湖洄游潜在的影响
}

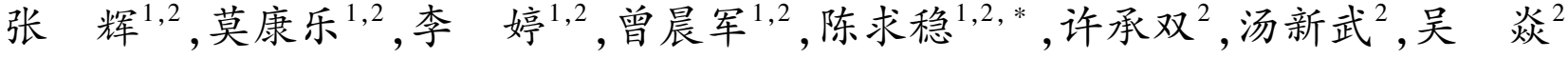 \\ 1 南京水利科学研究院水文水资源与水利工程科学国家重点实验室,南京 210029 \\ 2 南京水利科学研究院生态环境研究所,南京 210029
}

\begin{abstract}
摘要: 鄱阳湖是长江四大家鱼索饵、育肥的重要场所,近年来鄱阳湖出现了枯水季水位严重降低、枯水期延长、湿地面积缩小的 现象。为解决鄱阳湖水资源、水文、水生态等问题,建议在鄱阳湖人江水道兴建控制闸水利枢纽。然而,拟建的水利枢纽工程将 打破鄱阳湖与长江的天然连通性, 可能会对四大鱼类洄游过程产生影响。通过构建二维和三维水动力模型, 分析鄱阳湖水利枢 纽建设后人江水道与枢纽洄游通道的水动力学特征, 结合实验和文献获得的草鱼幼鱼和成鱼游泳能力参数, 阐明了枢纽建设对 草鱼洄游的影响。结果表明:在设计调度模式下,草鱼幼鱼人湖期间, 湖口段适宜通过天数达到 $83.74 \%$ 以上, 说明湖口及人江 水道的水动力条件对洄游的影响较小, 同时, 枢纽工程处在过鱼高峰期仍能保持较高的过闸效率; 草鱼成鱼出湖期间, 丰、平水 年闸前水动力条件对洄游的影响较小,仅在枯水年闸前流速几乎静止,草鱼适宜出湖天数偏低。在该调度模式下,水利枢纽建 设运行后鄱阳湖整体水动力条件能够满足草鱼洄游需求。目前设计的鱼道在高、低水位时期均出现局部流速过大的现象, 不满 足过鱼条件。从四大家鱼江湖洄游的角度为鄱阳湖水利枢纽工程设计和运行提供科学参考。
\end{abstract}

关键词 : 鄱阳湖; 水利枢纽工程; 水动力特征;江湖洄游

\section{The potential influence of the Poyang Lake Hydraulic Project construction on river-lake migration of grass carp}

ZHANG Hui ${ }^{1,2}$, MO Kangle ${ }^{1,2}$, LI Ting ${ }^{1,2}$,ZENG Chenjun ${ }^{1,2}$, CHEN Qiuwen ${ }^{1,2, *}$, XU Chengshuang ${ }^{2}$, TANG Xinwu ${ }^{2}$, WU Yan ${ }^{2}$

1 State Key Laboratory of Hydrology-Water Resources and Hydraulic Engineering, Nanjïng Hydraulic Research Institute, Nanjing 210029, China

2 Center for Eco-environmental Research, Nanjing Hydraulic Research Institute, Nanjing 210029, China

\begin{abstract}
Poyang Lake serves as the main feeding and fattening venue for the four major Chinese carps. In recent years, Poyang Lake has experienced a severe drop in water level during the dry season, prolonged dry season, and reduced wetland area. To tackle the problem of water resources, hydrology and water ecology in Poyang Lake, it is suggested to build a hydro-junction project which is proposed to be located at the channel connecting the Poyang Lake and the Yangtze River. Yet the to-be-built Poyang Lake Hydro-junction Project would impede the natural connection between Poyang Lake and the Yangtze River. The migration passage of the four major Chinese carps may be affected. To study the potential impact of the prospective hydro-junction project on the migration of grass carp, analysis was conducted on the hydrodynamic characteristics of the migration channel after the construction of Poyang Lake Hydro-junction Project using two-dimensional and three-dimensional hydraulic models. The swimming ability of grass carp was determined through experiment and literature review. According to the study results, more than $83.74 \%$ of the days suitable for fish passage at the entrance to
\end{abstract}

基金项目: 国家重点研发计划资助项目 (2016YFC0502205) ; 国家杰出青年科学基金资助项目(51425902)

收稿日期: 2020-09-11; 网络出版日期: 2021-08-30

*通讯作者 Corresponding author.E-mail: qwchen@ nhri.cn 
the lake. The hydrodynamic conditions at the entrance and the channel into the Yangtze River had an insignificant impact on the fish migration at the time when the juvenile grass carps entered the lake. Meanwhile, the gate chamber of hydro-junction project could still maintain a high passing efficiency during the peak period of fish migration. While under the designed scheduling mode, the hydrodynamic conditions in front of the hydraulic construction had little effect on fish migration in the years of wet and normal, but the days that were favorable for the fish departure from the lake decreased in dry years caused by almost static velocity in front of the hydraulic construction when the adult grass carps left the lake. The overall hydrodynamic conditions of Poyang Lake could meet the needs of the grass carp migration during the operation period of the Poyang Lake Hydro-junction Project. However, the current design of the fishway of the Poyang Lake Hydro-junction Project suffered the excessive flow velocity in some parts during high and low water level period, which dissatisfied the required passage conditions based on fish swimming ability under the existing scheduling mode. This study was expected to provide a scientific reference for the design and operation of the Poyang Lake Hydro-junction Project from the perspective of river-lake migration of the four major Chinese carps.

Key Words : Poyang Lake; hydro-junction project; hydrodynamic characteristic ; river-lake migration

鄱阳湖是中国最大的淡水湖泊,是长江中下游仅有的两个通江湖泊之一。作为一个吞吐、过水型季节性 湖泊,鄱阳湖与长江之间频繁的物质能量交换,江湖流水、静水生境的互补,共同构成了其独特的复合水生生 态系统 ${ }^{[1]}$ 。充足的淡水资源和优越的自然环境孕育出了生物资源丰富、生物多样性高、生物量大的鄱阳湖水 系。鄱阳湖不仅是我国重要的渔业产区和水生生物种质资源库 ${ }^{[2]}$, 还为长江中下游流域水生生物的繁殖和 鱼类的索饵、育肥提供了良好的栖息环境 ${ }^{\left[{ }^{3}\right]}$, 在保护长江水系的渔业资源和生物多样性方面发挥着极其重要 的作用。

受自然变化和水利工程建设、围湖造田、人工采砂等人类活动干扰的影响,长江中下游江湖水系水资源季 节性短缺、湖泊和洲滩湿地生态退化等水环境生态问题引起了广泛关注 ${ }^{[4]}$, 其中中游 “两湖” 问题尤为突 出 $^{[5]}$ 。近年来鄱阳湖出现枯水季水位严重降低, 枯水期延长, 湿地面积缩小的现象。而且受赣江、信江、修 河、抚河、饶河五大河来流水质下降和湖区资源开发的影响,湖体的水质与生态环境也逐渐恶化。为解决鄱阳 湖水资源问题, 有建议提出在鄱阳湖人江水道兴建控制闸水利枢纽 ${ }^{[6]}$ 。鄱阳湖水利枢纽工程的建设和运行 将打破鄱阳湖与长江的天然连通性,引起鄱阳湖湖区及湖口的水文水动力条件发生改变 ${ }^{[7]}$, 可能会导致鱼类 栖息地生境碎片化 ${ }^{[8]}$, 对江湖洄游性鱼类的出人湖行为造成直接影响。

四大家鱼(草、青、鲢、鳙) 是我国特有的江湖洄游性鱼类, 主要生长繁殖于我国长江及其通江湖泊中 ${ }^{[9]}$, 是长江水系主要养殖与捕捞的重要经济鱼类。每年 4-8 月四大家鱼当龄幼鱼和部分亲鱼顶流由江人湖生长 育肥, 10-12 月当年补充群体和育肥的成鱼由湖人江进行越冬洄游, 次年春季部分成鱼上溯至长江急流生境 产卵 ${ }^{[10]}$ 。鄱阳湖闸坝建设后上下游的水位落差及人江水道的水动力条件改变, 可能导致幼鱼难以从长江进 人通江湖泊摄食、育肥, 成鱼无法返回江道越冬、繁殖, 闸坝运行导致的静水也将使其迷失洄游方向,造成其无 法洄游完成生活史, 可能使四大家鱼天然资源量大幅下降 ${ }^{[11]}$ 。在四大家鱼中, 草鱼具有生长速度快、抗逆性 强且生物量占比大的特点 ${ }^{[12]}$, 草鱼资源数量的变化将直接影响我国淡水渔业的发展 ${ }^{[13]}$ 。因此, 有必要对枢 纽建成后草鱼江湖洄游的情况展开研究。

本文针对鄱阳湖鱼类洄游时期草鱼游泳行为偏好进行探索, 分别采用二维与三维水动力模型对水利枢纽 建设后鄱阳湖人江水道和水利枢纽闸区及鱼道水力学特性进行数值模拟, 分析其水动力条件变化对草鱼洄游 的影响,并从鱼类洄游路径保护的角度为枢纽的建设和运行提供科学参考。

\section{1 研究区概况与方法}

http ://www.ecologica.cn 


\section{1 研究区概况}

鄱阳湖位于北纬 $28^{\circ} 22^{\prime}-29^{\circ} 45^{\prime}$, 东经 $115^{\circ} 47^{\prime}-116^{\circ} 45^{\prime}$, 其湖面似葫芦形, 南部宽浅, 为主湖体, 北部人 江水道窄深并与长江直接相连, 是长江-鄱阳湖江湖洄游性鱼类的必经之路。拟建鄱阳湖水利枢纽设计闸址 正位于鄱阳湖人江水道 (图 1), 距离上游星子县 $12 \mathrm{~km}$, 下游距长江湖口 $27 \mathrm{~km}$ 。枢纽左岸为长岭山, 右岸连接 屏峰山, 两山之间湖面宽约 $2.8 \mathrm{~km}$, 为鄱阳湖人江通道最窄处, 坝址控制鄱阳湖水系流域面积约 $16.22 \mathrm{~km}^{2}$ 。
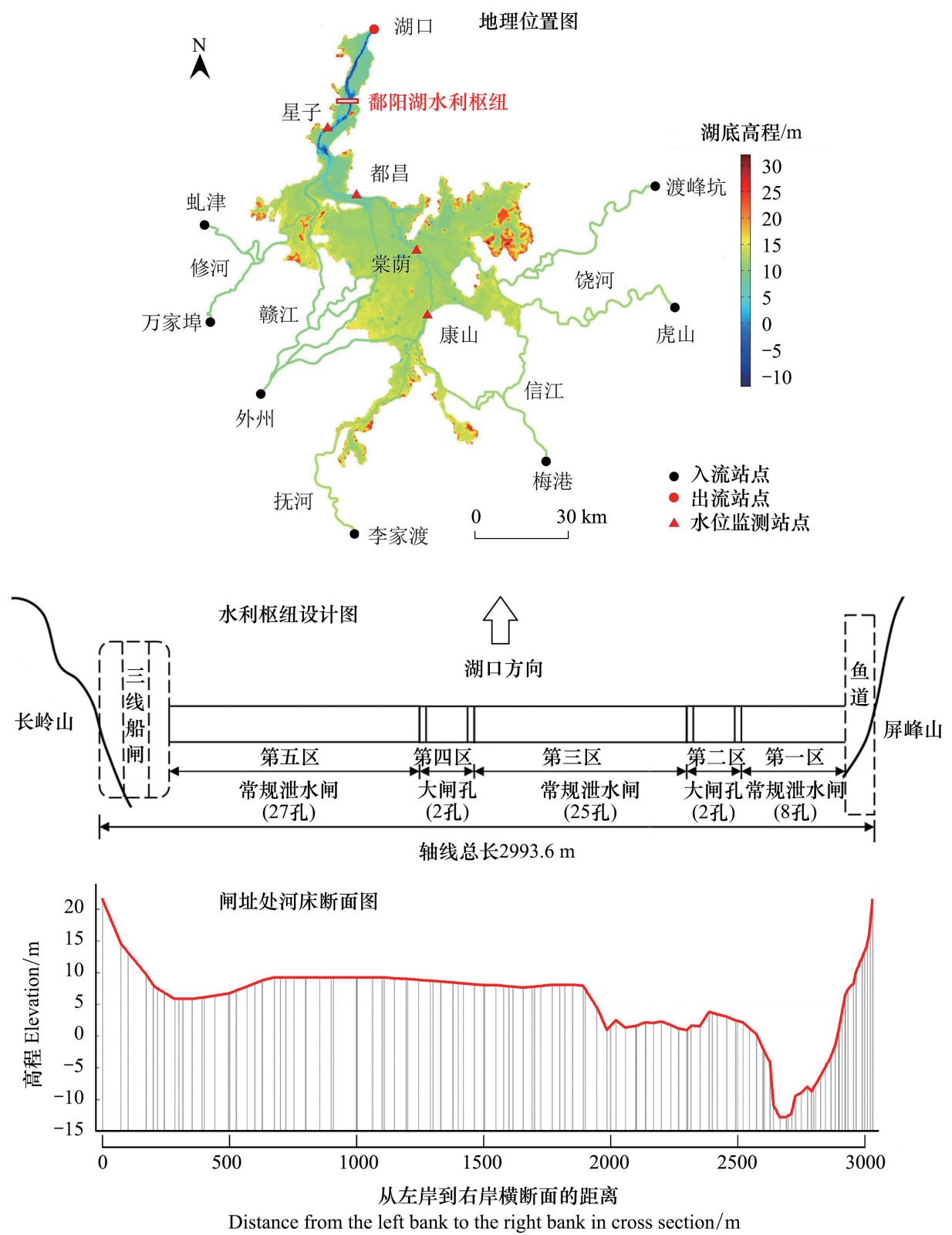

图 1 鄱阳湖水利枢纽工程示意图

Fig.1 Schematic diagram of Poyang Lake Hydraulic Project

鄱阳湖水利枢纽设计规划轴线总长 $2993.6 \mathrm{~m}$, 闸区拟设置五个泄水闸区 64 孔(图 1)。从右岸至左岸分 别为第一区 8 孔、第三区 25 孔、第五区 27 孔共计 60 孔常规泄水闸, 孔口净宽 $26 \mathrm{~m}$; 第二区 2 孔与第四区 2 孔 共计 4 个大孔闸, 孔口净宽 $60 \mathrm{~m}$, 汛期枢纽闸门全开保证江湖连通, 枯水期进行水位调控。枢纽左岸设置船 闸, 右岸并行布置低水位与高水位鱼道各一条, 均采用异侧坚缝式鱼道, 分别用于枯水期与汛后不同水位条件 下过鱼 ${ }^{[14]}$ 。 


\section{2 枢纽调度方式}

鄱阳湖水利枢纽目前尚处于论证阶段,根据其维系江湖关系、调枯不控洪等设计理念及工程特性,闸门的 初步调度方式主要有三种 (表 1), 本文选取方案一进行水动力特征模拟。

\section{表 1 不同研究课题下鄱阳湖水利枢纽调度方式}

Table 1 Operation modes of Poyang Lake Hydraulic Project under different research topics

\begin{tabular}{|c|c|c|c|c|}
\hline $\begin{array}{l}\text { 运行阶段 } \\
\text { Operation phase }\end{array}$ & $\begin{array}{l}\text { 时间 } \\
\text { Time }\end{array}$ & $\begin{array}{l}\text { 方案一 } \\
\text { Scheme I }\end{array}$ & $\begin{array}{l}\text { 方案二 } \\
\text { Scheme II }\end{array}$ & $\begin{array}{l}\text { 方案三 } \\
\text { Scheme III }\end{array}$ \\
\hline 主汛期 & 4 月 1 日一- 8 月 31 日 & 闸门全开, 江湖连通 & 闸门全开, 江湖连通 & - \\
\hline Flood period & 5 月 1 日一- 8 月 31 日 & - & - & 闸门全开, 江湖连通 \\
\hline $\begin{array}{l}\text { 蓄水期 } \\
\text { Storage water period }\end{array}$ & 9 月 1 日一 9 月 15 日 & $\begin{array}{l}\text { 当闸上水位高于 } 15.5 \mathrm{~m} \text { 时, 泄 } \\
\text { 水闸门全部敞开; 当闸上水位降 } \\
\text { 到或低于 } 15.5 \mathrm{~m} \text { 时, 控制闸门 } \\
\text { 开度, 使水位维持在 } 15.5 \mathrm{~m} \\
\text { 左右 }\end{array}$ & $\begin{array}{l}\text { 当闸上水位高于 } 15.5 \mathrm{~m} \text { 时, 泄 } \\
\text { 水闸门全部敞开; 当闸上水位降 } \\
\text { 到或低于 } 15.5 \mathrm{~m} \text { 时, 控制闸门 } \\
\text { 开度, 使水位维持在 } 15.5 \mathrm{~m} \\
\text { 左右 }\end{array}$ & $\begin{array}{l}\text { 当闸上水位高于 } 15.5 \mathrm{~m} \text { 时, 泄水闸 } \\
\text { 门全部敞开; 当闸上水位降到或低 } \\
\text { 于 } 15.5 \mathrm{~m} \text { 时,控制闸门开度,使水位 } \\
\text { 维持在 } 15.5 \mathrm{~m} \text { 左右 }\end{array}$ \\
\hline & 9 月 16 日一 9 月 30 日 & 水位消落至 $14.5 \mathrm{~m}$ & 水位消落至 $14.5 \mathrm{~m}$ & \\
\hline 补水期 & 10 月 1 日一 -10 月 10 日 & 水位消落至 $13.5 \mathrm{~m}$ & 水位消落至 $12.5 \mathrm{~m}$ & 水位消落至 $14 \mathrm{~m}$ \\
\hline Compensation period & $\begin{array}{l}10 \text { 月 } 11 \text { 日一 }-10 \text { 月 } 20 \text { 日 } \\
10 \text { 月 } 21 \text { 日一 }-10 \text { 月 } 31 \text { 日 }\end{array}$ & $\begin{array}{l}\text { 水位消落至 } 12.5 \mathrm{~m} \\
\text { 水位消落至 } 11.5 \mathrm{~m}\end{array}$ & & \\
\hline 供水期 & 11 月 1 日一-11月 30 日 & 水位消落至 $10 \mathrm{~m}$ & 水位维持在 $12.5 \mathrm{~m}$ 左右 & 水位维持在 $14 \mathrm{~m}$ 左右 \\
\hline Water supply period & 12 月 1 日一 -2 月 28 日 & 水位维持在 $10 \mathrm{~m}$ 左右 & & \\
\hline 泄水期 & 3 月 1 日一 -3 月 31 日 & 水位维持在 $10 \mathrm{~m}$ 左右 & 水位消落至 $11 \mathrm{~m}$ & - \\
\hline Water release period & 3 月 1 日一 4 月 30 日 & - & - & 水位消落至 $12 \mathrm{~m}$ \\
\hline
\end{tabular}

鄱阳湖水利枢纽调度方案引自参考文献 ${ }^{[15]}$; 水位为黄海高程

\section{3 水动力特性模拟}

(1) 人江水道二维水动力模型

鄱阳湖属于典型的季节性宽浅型湖泊,湖泊水体在垂向上流速分层不明显,可采用布辛涅斯克 (Boussinesq) 假定和静水压强假定下的 Navier-Stokes 方程对鄱阳湖水利枢纽建设后的湖区及人江水道水动力 变化情况进行模拟,并通过交替隐式法 (ADI) 对 $\sigma$ 坐标下的控制方程组进行离散求解。正交曲线坐标下的二 维水动力模型详细推导过程见参考文献 $[16]$ 。

基于 2002 年江西省水利科学研究院实测地形数据, 以整个鄱阳湖湖区为计算区域,利用正交曲线网格对 其进行格网化, 并对人江水道段的网格进行了加密, 最终计算区域划分网格总数量为 72250 ,网格分辨率范围 为 $148-293 \mathrm{~m}$,网格节点余弦值均小于 0.02 ,纵横比和平滑性分别在 $[1,1.2]$ 和 $[1,2]$ 之间。

上游边界条件根据“皮尔逊 III 型”曲线选取丰、平、枯水年对应的五河全年逐日流量(表 2) 并以相应的位 置信息作为人汇点, 下游边界为湖口水文站逐日实测水位 (实测数据均来源江西省水利厅)。枢纽处以设计 调度模式下的水位控制过程为边界条件,实现鄱阳湖水利枢纽工程的情景模拟。鄱阳湖流场主要受到五河来 水倾泻与长江的顶托作用来驱动, 重力流为主要湖流流型, 风生流次之且对湖流的影响仅体现在湖区中部, 对 人江水道水动力的影响比较微弱 ${ }^{[17]}$, 因此不考虑风生流对入江水道流场的影响。模型计算启动条件为 “冷启 动” (即湖区水体初始为静止状态), 其他模型参数设置见表 2 。

(2) 枢纽工程局部三维水动力模型

枢纽处流体近似于明渠不可压缩液体湍流流动, 闸室和鱼道等关键结构处流场紊动剧烈且常伴有漩涡和 回流的产生。为得到枢纽工程三维精细流场, 选用雷诺应力平均 RNG $k-\varepsilon$ 紊流模型建立数值模型, 采用流体 体积法 (VOF) 对水体自由表面进行追踪, 并通过 SIMPLEC 算法进行数值求解。控制方程及推导过程见参考 文献 ${ }^{[18]}$ 。 
根据谭细畅等人 ${ }^{[19]}$ 对四大家鱼幼鱼游泳习性的研究, 结合枢纽工程选址地形条件 (图 1), 确定靠近河道 左右两岸的深水河槽为鱼类洄游迁徙的主要通道。根据鱼类在人江水道中的洄游行为特点, 本文选取右岸主 河槽泄水闸一区、二区与鱼道为计算区域,模型起始与终止断面分别位于原型坝轴线上游 $210 \mathrm{~m}$ 和下游 $395 \mathrm{~m}$ 处。由于枢纽闸区与鱼道结构复杂,不同区域结构尺寸差异大、模拟区域大,因此对模拟区域进行非结构化四 面体网格划分, 并对闸区和鱼道等局部结构进行加密,网格尺寸在 $0.1-1.0 \mathrm{~m}$ 之间, 总数约为 1600 万, 在保证 精度的同时,将非结构网格转化为多面体网格以减少网格数量,最终网格数量约为 450 万。

表 2 鄱阳湖五河年均流量典型年份选择及模型参数确定

Table 2 Selection of typical years of average annual flow of the five rivers and determination of model parameters of Poyang Lake

\begin{tabular}{|c|c|c|c|c|}
\hline & $\begin{array}{l}\text { 典型年份 } \\
\text { Typical years }\end{array}$ & $\begin{array}{l}\text { 设计频率 } \\
\text { Design frequency/\% }\end{array}$ & $\begin{array}{l}\text { 流量 } \\
\left.\text { Flow rate/( } \mathrm{m}^{2} / \mathrm{s}\right)\end{array}$ & $\begin{array}{l}\text { 对应年份 } \\
\text { Year }\end{array}$ \\
\hline 模拟时期 & 丰水年 & 20 & 4744 & 2002 \\
\hline \multirow[t]{2}{*}{ Simulation period } & 平水年 & 50 & 3726 & 2005 \\
\hline & 枯水年 & 90 & 2545 & 2007 \\
\hline 模型参数 & 重力加速度/ (m/ s²) & 水体密度/ $\left(\mathrm{kg} / \mathrm{m}^{3}\right)$ & 水平涡动粘性系数 & 时间步长/s \\
\hline \multirow[t]{3}{*}{ Model parameter } & 9.81 & 1000 & 1.00 & 30 \\
\hline & 干湿网格临界水深/m & 主河槽区域䊁率 & 边滩和多水生植物区域䊁率 & 初始水位 \\
\hline & 0.05 & 0.02 & $0.03-0.06$ & 年平均水位 \\
\hline
\end{tabular}

本文选取洪水频率为 $50 \%$ 的平水年 (2005 年) 为典型年进行模拟。枢纽工程和鱼道模型上游人口边界均 采用速度进口; 下游出口分别采用自由出流和压力出口; 顶部均采用压力边界, 体积分数为 0 ; 枢纽工程模型 左侧边界采用对称边界,其他壁面均为无滑移壁面 (详细边界信息及参数见表 3)。以各模拟时期的河道水位 作为计算区域的初始水位, 鱼道独立运行时采用设计运行水深作为鱼道初始水深, 初始流场静止。计算先采 用一阶迎风离散格式, 待计算稳定以后改用二阶迎风格式进行计算, 以提高模拟精度。压力项采用体积力加 权离散,采用自适应迭代法进行计算。

表 3 平水年不同模拟时期枢纽闸区及鱼道边界条件及参数确定

Table 3 Determination of boundary conditions and parameters of the gate area and fishway of different simulation periods in normal year

\begin{tabular}{|c|c|c|c|c|c|c|}
\hline $\begin{array}{l}\text { 模拟时期及边界条件 } \\
\text { Simulation period and } \\
\text { boundary condition }\end{array}$ & $\begin{array}{l}\text { 模拟时期 } \\
\text { Simulation } \\
\text { period }\end{array}$ & $\begin{array}{c}\text { 实际来流量 } \\
\text { Flow rate/ } \\
\left(\mathrm{m}^{2} / \mathrm{s}\right)\end{array}$ & $\begin{array}{c}\text { 上游( 设计) 水位 } \\
\text { Upstream design } \\
\text { level } / \mathrm{m}\end{array}$ & $\begin{array}{c}\text { 对应流速 } \\
\text { Flow velocity/ } \\
\qquad(\mathrm{m} / \mathrm{s})\end{array}$ & $\begin{array}{c}\text { 下游( 设计) 水位 } \\
\text { Downstream } \\
\text { design level/m }\end{array}$ & $\begin{array}{c}\text { 家鱼人湖阶段 } \\
\text { Period of fish } \\
\text { entering the lake }\end{array}$ \\
\hline & $\begin{array}{l}\text { 低水位 } \\
\text { (4月 } 4 \text { 日) }\end{array}$ & 5446.61 & 9.67 & 0.36 & - & 开始人湖 \\
\hline & $\begin{array}{l}\text { 涨水位 } \\
\text { (5月 } 25 \text { 日) }\end{array}$ & 14957.67 & 13.75 & 0.6 & - & 人湖增加 \\
\hline & $\begin{array}{l}\text { 高水位 } \\
\text { (7月 } 21 \text { 日) }\end{array}$ & 2916.85 & 14.2 & 0.12 & - & 人湖高峰 \\
\hline & $\begin{array}{l}\text { 低水位鱼道 } \\
\text { (3月独立运行) }\end{array}$ & 2787.6 & 9.5 & 0.21 & 5.35 & - \\
\hline & $\begin{array}{l}\text { 高水位鱼道 } \\
\text { (9月独立运行) }\end{array}$ & 3110.5 & 14.5 & 0.12 & 8.64 & - \\
\hline \multirow[t]{2}{*}{$\begin{array}{l}\text { 模型参数 } \\
\text { Model parameter }\end{array}$} & $\begin{array}{l}\text { 壁面粗糙度 } \\
\text { Surface } \\
\text { roughness/m }\end{array}$ & $\begin{array}{c}\text { 大气压强 } \\
\text { Pressure/Pa }\end{array}$ & $\begin{array}{l}\text { 时间步长 } \\
\text { Time step/s }\end{array}$ & $\begin{array}{l}\text { 迭代次数 } \\
\text { Interations }\end{array}$ & $\begin{array}{c}\text { 进出口质量差 } \\
\text { Mass } \\
\text { flow rate }\end{array}$ & $\begin{array}{c}\text { 残差精度 } \\
\text { Residual } \\
\text { error precision }\end{array}$ \\
\hline & 0.001 & $1.01 \times 10^{5}$ & 0.2 & 20 & $\leqslant 0.01$ & $\leqslant 10^{-3}$ \\
\hline
\end{tabular}

1.4 草鱼洄游能力实验

鱼类感应流速、临界流速等游泳行为特性在过鱼建筑中的应用和鱼类保护方案的制定过程中具有重大意 $义^{[20]}$ 。人湖期间,主要以草鱼幼鱼临界流速判断其能顶流通过流速屏障; 出湖期间,主要以草鱼成鱼感应流 
速判断其能否感知洄游方向。本文根据鄱阳湖水利枢纽工程现阶段设计,采用五孔低水头闸坝模型对鄱阳湖 草鱼江湖洄游时的过闸机制进行探究, 以确定草鱼在洄游通过低水头闸坝时的流速阈值 ${ }^{[21]}$ 。选取体长 $(6.56 \pm 0.78) \mathrm{cm}$ 、体重 $(8.78 \pm 0.48) \mathrm{g}$ 的草鱼作为实验对象, 根据鄱阳湖人江水道实际流速, 将实验流速设置 为 $0.1-0.7 \mathrm{~m} / \mathrm{s}$, 以还原草鱼通过鄱阳湖水利枢纽工程时的行为特征。每种流场工况进行 6 组重复实验, 每 组 10 尾。从图 2 可以看出, 在人口流速为 $0.1 \mathrm{~m} / \mathrm{s}$ 的情况下, 草鱼就能够有效的感应流速方向, 表现出明显地 趋流行为, 并快速通过闸孔。人口流速范围在 $0.4 \mathrm{~m} / \mathrm{s}$ 以下时, 草鱼过闸尾数一直保持在较高的水平, 且平均 过闸时间在 $2 \mathrm{~min}$ 左右。当流速超过 $0.5 \mathrm{~m} / \mathrm{s}$ 时, 出现个别实验组通过率较低的现象, 且通过时间明显延长。 当人口流速提高到 $0.7 \mathrm{~m} / \mathrm{s}$ 时, 仅有少数草鱼能够顶流通过闸室, 且多组通过时间超过 $10 \mathrm{~min}$, 不利于草鱼幼 鱼通过闸区,而人口流速为 $0.6 \mathrm{~m} / \mathrm{s}$ 时通过率较高、通过时间较短, 因此选取中值 $0.65 \mathrm{~m} / \mathrm{s}$ 为草鱼幼鱼过闸的 临界流速。
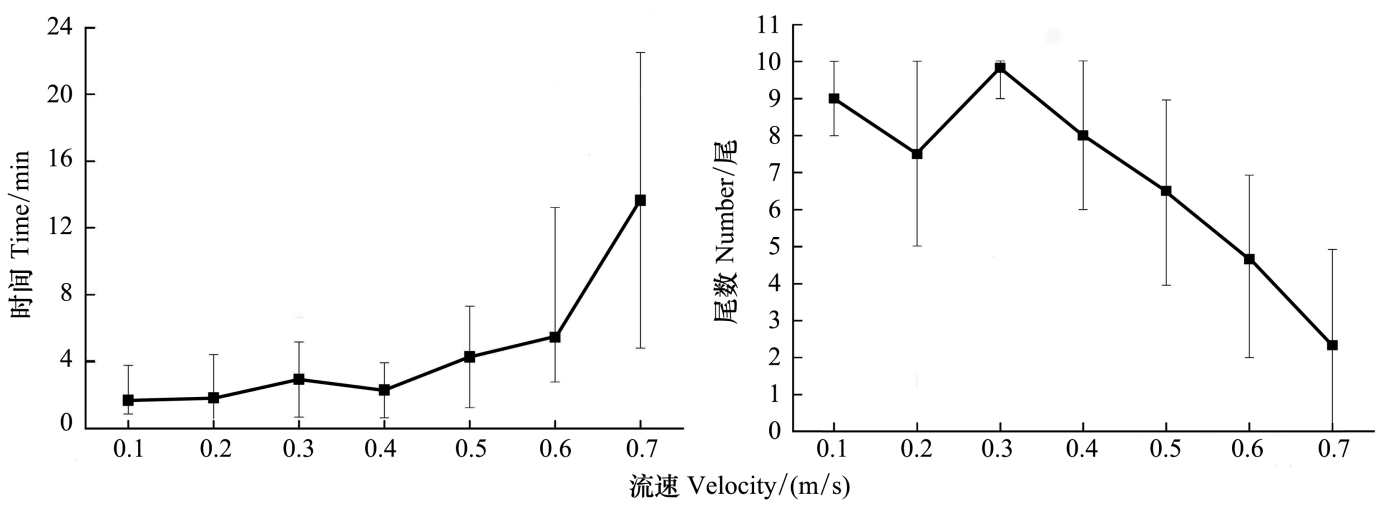

图 2 草鱼洄游能力实验结果

Fig.2 Experimental results of swimming ability of grass carp

通过表 4 研究结果对比可以看出,已有研究与本实验结果具有较好的一致性,出现的差异可能是由于幼 鱼体长和实验条件差异所致。最终确定鄱阳湖草鱼幼鱼洄游时期的临界流速为 $0.65 \mathrm{~m} / \mathrm{s}$, 感应流速为 0.10 $\mathrm{m} / \mathrm{s}$ 。白艳勤 ${ }^{[22]}$ 等人研究成果表明, 草鱼的感应流速大小随体长的增长不显著, 因此感应流速阈值分析在分 析成鱼出湖阶段仍然适用。

表 4 与其他相关草鱼行为学实验结果对比

Table 4 Compared with other experimental results on grass carp behavior

\begin{tabular}{|c|c|c|c|c|c|}
\hline $\begin{array}{l}\text { 来源 } \\
\text { Data source }\end{array}$ & $\begin{array}{c}\text { 体长 } \\
\text { Length/cm }\end{array}$ & $\begin{array}{c}\text { 感应流速 } \\
\text { Induction velocity/ } \\
(\mathrm{cm} / \mathrm{s})\end{array}$ & $\begin{array}{l}\text { 来源 } \\
\text { Data source }\end{array}$ & $\begin{array}{c}\text { 体长 } \\
\text { Length/cm }\end{array}$ & $\begin{array}{c}\text { 临界流速 } \\
\text { Critical velocity/ } \\
(\mathrm{cm} / \mathrm{s})\end{array}$ \\
\hline 本研究 Our study & $6.56 \pm 0.78$ & 10.00 & 本研究 Our study & $6.56 \pm 0.78$ & 65.00 \\
\hline 白艳勤 [22] & $9.64 \pm 3.12$ & 8.00 & 房敏 [23] & $7.50 \pm 0.35$ & $78.63 \pm 3.36$ \\
\hline 曹平 [24] & $13.16 \pm 2.85$ & 13.00 & 龚丽 ${ }^{[25]}$ & $8.85 \pm 0.85$ & $62.93 \pm 5.31$ \\
\hline
\end{tabular}

\section{2 结果}

\section{1 水利枢纽建设对人江水道水动力特征的影响}

人江水道二维水动力模型模拟结果表明 (图 3), 在设计调度模式下, 人江水道各典型年内流速均相对较 缓,整体流速在 $0.02-0.64 \mathrm{~m} / \mathrm{s}$ 之间。主流区明显且分布范围较窄, 受湖口断面急剧缩窄影响,最大流速一般 发生在湖口断面。在幼鱼洄游上溯期间 ( 4-8 月), 水位上升期,各水平年流速普遍较低,湖口最大流速在 0.4 $\mathrm{m} / \mathrm{s}$ 左右, 闸前流速在 $0.18 \mathrm{~m} / \mathrm{s}$ 以下; 高水位期, 丰水年湖口段最大流速达到了 $0.74 \mathrm{~m} / \mathrm{s}$, 闸前流速相对较快, 
平、枯水年人江水道和湖口流速都较低。在成鱼洄游出湖期间 (10-12 月), 水位下降期,各水平年人江水道 流速整体偏高, 湖口流速均有所加快, 最大流速接近 $0.8 \mathrm{~m} / \mathrm{s}$, 闸前流速普遍在 $0.22 \mathrm{~m} / \mathrm{s}$ 左右; 低水位期, 丰水 年整体流速较高, 湖口和闸前流速分别达到了 $1.0 \mathrm{~m} / \mathrm{s}$ 和 $0.41 \mathrm{~m} / \mathrm{s}$, 且明显高于平、枯水年, 尤其枯水年闸前流 速几乎静止。从入江水道水动力特征可以看出, 湖口流速是制约鱼类人湖的关键因素, 低水位期闸前流速也 可能对鱼类出湖造成影响。

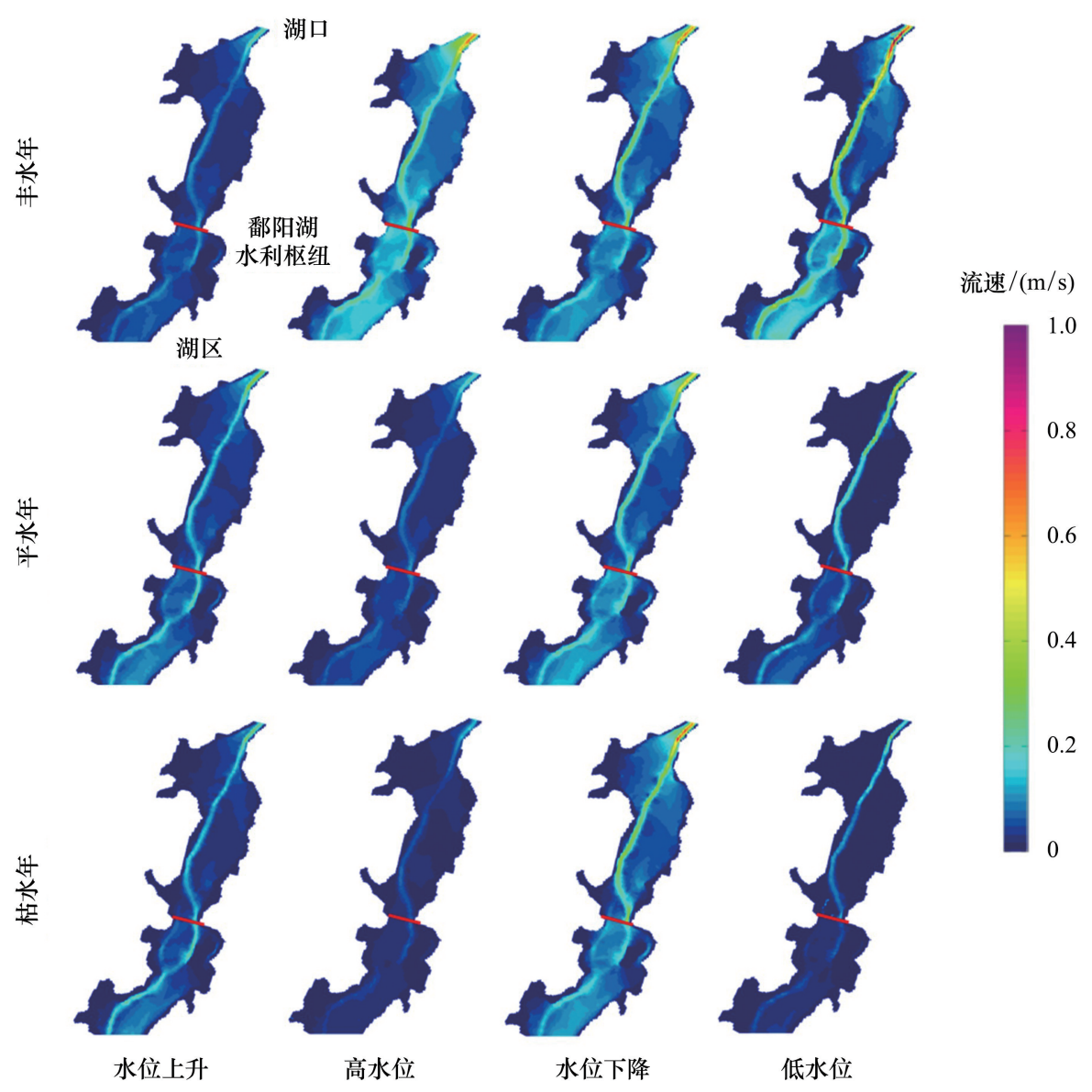

图 3 各典型年份不同水期入江水道流场图

Fig.3 Spatial distribution of river flow field in different water periods of each typical year

\section{2 利枢纽建筑局部水动力学特征}

鄱阳湖水利枢纽工程闸区的三维水动力模型模拟结果表明 (图 4), 在鱼类洄游上溯期间 (闸门全开、江湖 连通时期), 枢纽右岸闸区整体流速处于较高的水平, 且闸前流速低于闸后流速。低水位期,右岸来水主要从 泄水闸一区 4-6 号闸孔通过, 水面流速在 $0.65 \mathrm{~m} / \mathrm{s}$ 左右, 近岸闸孔流速较缓, 水面流速在 $0.25 \mathrm{~m} / \mathrm{s}$ 左右, 泄 水闸一区 7 号孔以左闸室流速较缓,在 $0.3 \mathrm{~m} / \mathrm{s}$ 左右。涨水位期, 水流主要从泄水闸一区通过,水面处流速在 $0.75 \mathrm{~m} / \mathrm{s}$ 左右, 泄水闸二区闸前流速相对较缓, 整体流速在 $0.53 \mathrm{~m} / \mathrm{s}$ 左右, 闸后水面流速在 $0.65 \mathrm{~m} / \mathrm{s}$ 左右。 高水位期,除近岸 $1-2$ 闸孔处流速较低之外, 各闸孔流速分布较一致, 闸前水面流速较缓为 $0.27 \mathrm{~m} / \mathrm{s}$, 但闸后 流速有所加快, 水面处流速在 $0.5 \mathrm{~m} / \mathrm{s}$ 左右。

鱼道在各水位条件下 (表 3) 独立运行的水动力特性模拟结果表明 (图 5), 本工程低、高水位期鱼道内部 池室均存在形态较好回流区, 流速在 $0.2 \mathrm{~m} / \mathrm{s}$ 左右, 主流区流速普遍在 $0.45 \mathrm{~m} / \mathrm{s}$ 以上, 部分池室间竖缝处最大 断面流速分别达到 $1.08 \mathrm{~m} / \mathrm{s}$ 和 $1.05 \mathrm{~m} / \mathrm{s}$ 。转弯段外侧主流区流速分别达到 $1.26 \mathrm{~m} / \mathrm{s}$ 和 $0.75 \mathrm{~m} / \mathrm{s}$, 回流区范围 较大且, 内侧流速超过了 $0.6 \mathrm{~m} / \mathrm{s}$ 。下游人口段水流流态较好, 主流区和坚缝处流速均在 $0.5-0.72 \mathrm{~m} / \mathrm{s}$ 之间。 


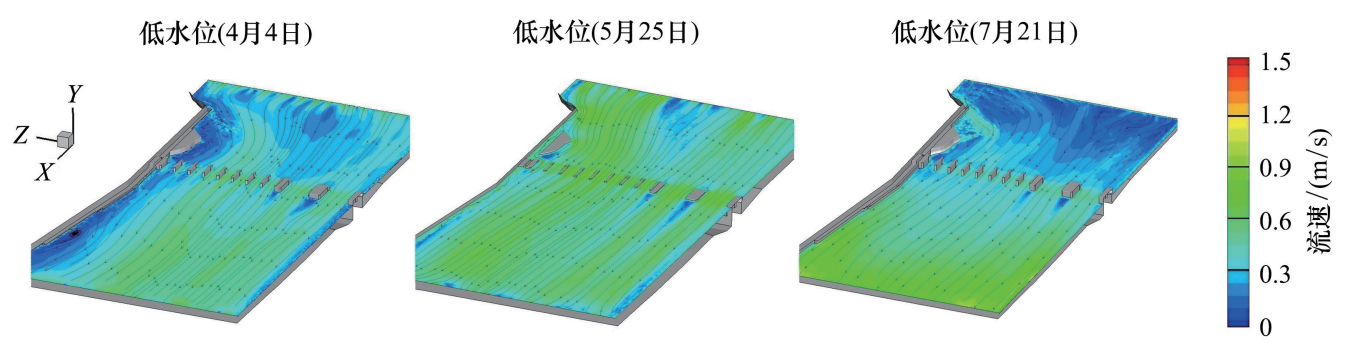

图 4 平水年各典型水期枢纽工程闸区流场图

Fig.4 Spatial distribution of flow field in hydro-junction gate area of each typical time periods in normal year

两种鱼道上游出口段坚缝处流速都较大,低水位鱼道出口段局部高流速区达到 $1.62 \mathrm{~m} / \mathrm{s}$ 。

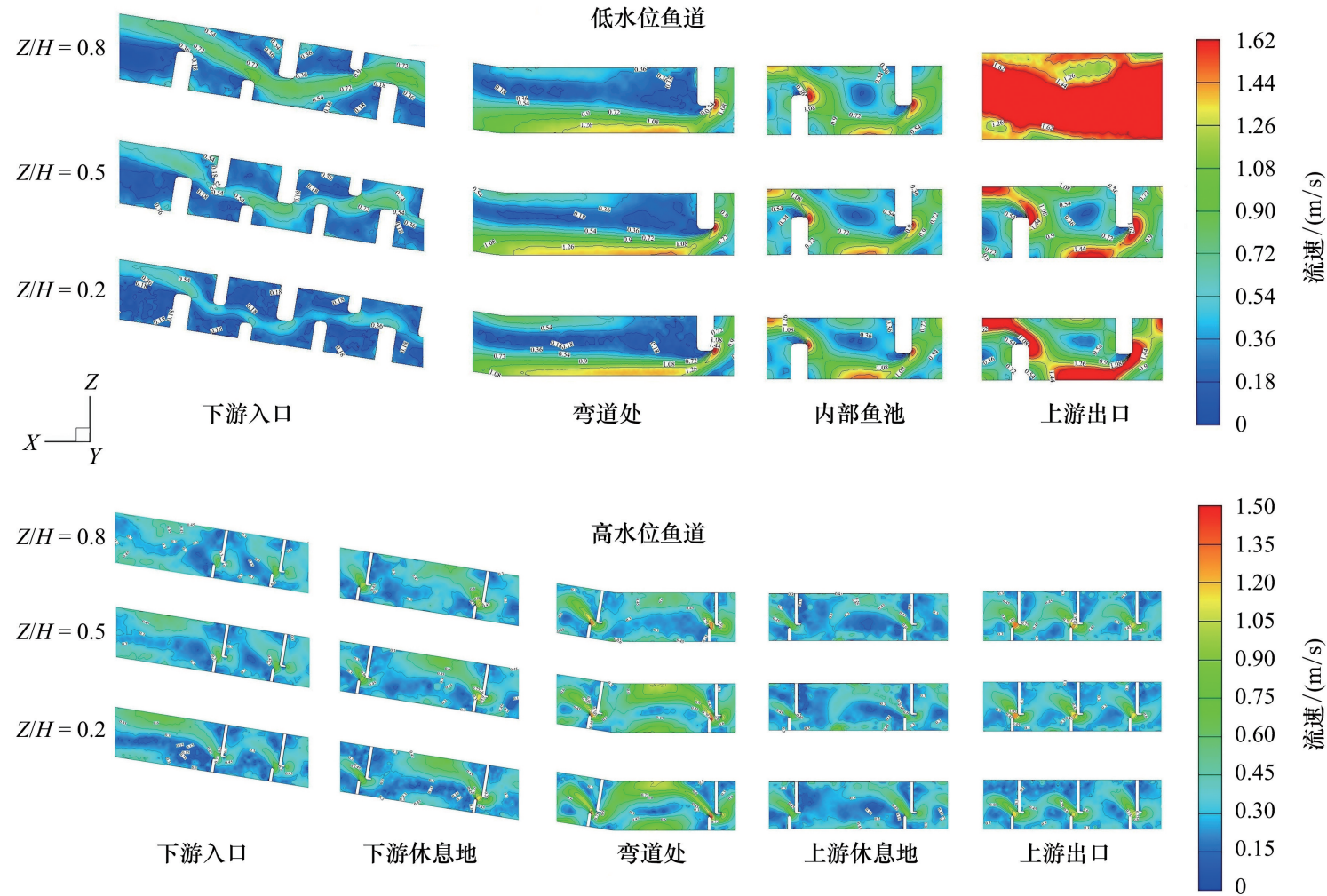

图 5 鱼道不同时期、不同水深流场图 ( $Z / H$ 表示不同层面水深与总水深的比值)

Fig.5 Flow field distribution of fishways in different periods and depths

\section{3 讨论}

\section{1 人江水道水动力特征变化对草鱼洄游潜在影响}

鄱阳湖水文情势受上游五河和长江来水的双重作用,每年 4 月至 7 月为五河来流主汛期, 8 月至 9 月来 流逐渐减少, 10 月至次年 3 月为枯水期,狭长的湖口水道与长江自然相通, 长江干流来水量将直接影响着鄱 阳湖口泄流能力以及人江水道的水动力条件, 尤其体现在长江汛后蓄水期 ${ }^{[26]}$ 。水位上升期, 鄱阳湖水利枢纽 闸门全开保持江湖联通, 湖区水位处于较低的水平,虽然五河来水量开始增加,但此时三峡工程仍处于高水位 运行阶段, 对下游江道均衡补水直至 6 月上旬 ${ }^{[27]}$, 鄱阳湖与长江干流水头相差较小, 洄游通道及湖口整体流 速较缓, 对草鱼上溯几乎没有影响, 但长江中下游洄游性鱼类进入鄱阳湖时间一般集中在 7-8 月 ${ }^{[28]}$, 因此江 
湖连通初期鱼类人湖数量有限。高水位期, 湖区水位达到比较高的水平,五大水系来水逐渐减少, 鄱阳湖湖口 宣泄量受湖区高水位和长江主汛顶托的共同作用 ${ }^{[29]}$, 导致丰水年湖口和人江水道流速有所增加, 但未达到峰 值,这可能会对一些游泳能力较弱的草鱼幼鱼造成洄游障碍; 对平、枯水年的影响较小,甚至在枯水年的高水 位期还发生了江水倒灌人湖的现象 ${ }^{[15]}$ 。鄱阳湖中与草鱼具有相似习性的洄游性鱼类约 18 种 ${ }^{[30]}$, 其中鳙鱼、 胭脂鱼、鲟科和鳗鲡科等游泳能力弱于草鱼的鱼类也可能受到影响。水位下降期和低水位期,湖区在鄱阳湖 水利枢纽的拦蓄作用下仍维持一定的水位,而受三峡水库汛末蓄水的影响, 长江干流水位显著降低 ${ }^{[31]}$, 在水 力梯度的作用下, 人江水道与湖口的流速明显加快。赖格英等人 ${ }^{[32]}$ 曾指出鄱阳湖水利枢纽工程的调度对长 江枯水期流量则有一定增排作用，但该时段鱼类基本上已经完成人湖洄游,因此水位下降期和低水位期湖口 水动力条件不作为人湖判断条件。通常闸坝的建设在提升库区水位的同时,也会导致库区水流流速变缓。低 水位期, 鄱阳湖水利枢纽工程对湖区水位抬升和流速减缓的影响主要体现在湖泊北部的水道中 ${ }^{[7]}$, 人江水道 流速对鱼类进出湖区影响不大, 闸前流速的改变可能会对鱼类成鱼出湖造成不利影响。

3.2 水利枢纽建筑局部水动力学特征对草鱼洄游潜在影响

结合水下地形资料可知 ${ }^{[15]}$, 鄱阳湖水利枢纽闸址处河道右岸为主泓, 区域前后为深槽, 上游来流的水流 形态受到右岸屏峰山地形的阻挡,迫使水流涌向河道主鸿, 导致泄水闸一区 4-6 号闸孔流速偏高, 明显高于 岸边流速, 右岸近岸处闸孔很可能成为幼鱼上溯的主要通道。涨水位期, 五河主汛导致湖水位快速雍高 ${ }^{[33]}$, 增大了闸区的宣泄流量, 可能会对幼鱼上溯产生一定的影响。受低、高水期来流相对较小和右岸闸前深槽的 共同影响, 形成了闸前水深较深、流速偏低, 闸后流速加快的现象, 这能够避免抵达上游鱼类在枢纽附近易被 高速水流再次卷人泄水闸,顺水流被冲到下游区, 因此闸前缓慢的水流流态对鱼类洄游人湖是有利的。

坚缝式鱼道水流特征在连续池室之间不断转换, 除转弯段和上游出口段外, 池室内通常都存在 $1-2$ 个范 围适宜的缓流区, 其速度远低于竖缝处速度。Wang 等人 ${ }^{[34]}$ 研究成果表明, 隔板后侧的缓流区能为鱼类提供 充足的休礉空间, 因此本工程鱼道内部池室缓流区形态对鱼类的上溯是有利的。内部池室主流区流速普遍在 草鱼幼鱼适宜流速区间内, 但部分池室间坚缝处断面流速过大, 即使草鱼、青鱼等游泳能力较强的洄游性鱼类 也难以通过。转弯段流态主要是由于受外侧壁面的挤压作用,水流方向发生改变 ${ }^{[35]}$, 造成主流区贴壁流动并 伴随着流速较快、尺度较大的回流区, 可能会导致部分鱼类在池室内徘徊, 降低上溯效率 ${ }^{[36]}$ 。高、低水位鱼道 最不利流态均发生在上游出口段, 出口段坚缝处流速均超过了 $1.0 \mathrm{~m} / \mathrm{s}$, 这将导致鱼类无法完成上溯。

\section{3 鄱阳湖水利枢纽建设对草鱼江湖洄游潜在影响综合分析}

鱼类洄游路径周围流场变化是影响鱼类行为动机的重要因素 ${ }^{[37]}$, 人湖期间各时期流速极大值主要出现 在湖口及工程枢纽处, 当流速屏障超出鱼类上溯能力时, 将导致鱼类无法成功上溯 ${ }^{[35]}$; 出湖期间鱼类顺流而 至长江干流, 不存在顶流洄游行为, 而受枢纽调度的影响, 闸前洄游通道流速低于草鱼感应流速, 这可能导致 草鱼成鱼迷失向下游迁徙的方向感而滞留在库区内 ${ }^{[38]}$; 闸后洄游通道流速能够满足草鱼流速感应需求, 认为 闸后通道流场有利于成鱼出湖。因此, 本文以 4-8 月鄱阳湖湖口、枢纽闸区及鱼道水动力特征与幼鱼临界流 速阈值判断能否人湖, 以 10-12 月闸前洄游通道水动力特征与成鱼感应流速阈值判断能否出湖。

表 5 表明,草鱼幼鱼洄游上溯期间,该设计调度模式可以有效减缓枢纽建设对湖口流速的影响,在各水平 年江湖连通期内可将草鱼幼鱼适宜通过天数保证在 $83.74 \%$ 以上。人江水道内主流区明确且流速大小适宜草 鱼幼鱼上溯, 两侧缓流区流速较低, 对草鱼幼鱼洄游感应主流方向及中途休咊是有利的 ${ }^{[39]}$ 。已有研究表明, 流速较小、流速范围和水深范围较大的右岸近岸区域是草鱼幼鱼洄游人湖的主要通道 ${ }^{[00]}$ 。据此, 结合鄱阳湖 水利枢纽工程近岸闸室水动力条件进行分析, 结果表明, 右岸泄水闸一、二区对草鱼幼鱼人湖影响较小, 只有 涨水位期上溯通过存在困难,但在后续的高水期闸区适宜流速占比达到 $82.4 \%$ 以上,与草鱼幼鱼主要人湖时 间相符 ${ }^{[28]}$ 。因此江湖连通期保持闸门全开, 闸室水流条件能够满足草鱼幼鱼的上溯需求。鱼道独立运行期 间, 鱼道上游出口及部分坚缝的流速远远超出草鱼幼鱼上溯适宜流速范围, 出口段水流湍急、坚缝处流速过大 是导致鱼道失败的关键因素。故本工程中鱼道对草鱼幼鱼洄游人湖的辅助作用十分有限。 
表 5 各时期、节点草鱼洄游情况

Table 5 Migratory situation of grass carp in each periods and locations

\begin{tabular}{|c|c|c|c|c|c|c|c|c|c|}
\hline \multirow{2}{*}{$\begin{array}{l}\text { 时期 } \\
\text { Period }\end{array}$} & \multicolumn{4}{|c|}{$\begin{array}{c}\text { 人江水道 } \\
\text { Channel connecting Poyang } \\
\text { Lake and the Yangtze River }\end{array}$} & \multirow{2}{*}{$\begin{array}{l}\text { 时期 } \\
\text { Period }\end{array}$} & \multicolumn{4}{|c|}{$\begin{array}{c}\text { 枢纽过鱼通道 } \\
\text { Migration passage of hydraulic construction }\end{array}$} \\
\hline & & 人湖 & $\begin{array}{l}\text { 闸前 } \\
\text { 数 }\end{array}$ & $\begin{array}{l}\text { 出湖天 } \\
1 \%\end{array}$ & & & $\begin{array}{l}\text { X人湖适宜 } \\
\text { 间占比 } / \%\end{array}$ & & 鱼道 \\
\hline 丰水年 (2002 年) Wet year & V & 87.80 & V & 100 & $\begin{array}{l}\text { 低水位 } \\
4 \text { 月 } 1 \text { 日一-4月 } 30 \text { 日 }\end{array}$ & V & 87.02 & $x$ & $\begin{array}{l}\text { 局部流速过大, } \\
\text { 不满足过鱼条件 }\end{array}$ \\
\hline 平水年(2005 年) Normal year & V & 83.74 & V & 53.26 & $\begin{array}{l}\text { 涨水位 } \\
5 \text { 月 } 1 \text { 日一7月 } 4 \text { 日 }\end{array}$ & V & 51.95 & & \\
\hline 枯水年(2007 年) Dry year & V & 88.62 & $\triangle$ & 32.61 & $\begin{array}{l}\text { 高水位 } \\
7 \text { 月 } 5 \text { 日一8 月 } 31 \text { 日 }\end{array}$ & V & 94.6 & & \\
\hline
\end{tabular}

湖口适宜人湖天数占比 $=$ 适宜人湖天数 $/ 4-8$ 月份天数; 闸前适宜出湖天数占比 $=$ 适宜出湖天数 $/ 10-12$ 月份天数; 闸区人湖适宜空间占比 $=$ 闸室适宜通过面 积/断面总面积; $\mathrm{V}$ : 表示可以过鱼(占比 50\%以上); $\mathrm{x}$ :表示不能过鱼(占比 10\%以下); $\triangle$ :表示少部分可以通过(占比 10\%一 $50 \%$ )

草鱼成鱼洄游出湖期间,调控期湖水位升高,湖流特征由 “河相”转变为“湖相”。鄱阳湖水利枢纽工程对 枯水年枯水期湖区水位抬升和流速减缓的影响程度最大, 导致枯水年成鱼适宜出湖天数占比偏低, 为 $32.61 \%$, 丰水年和平水年闸前流态对草鱼成鱼出湖流速需求的满足度都较高, 因此无需针对成鱼出湖对枢纽 运行进行调控。综上所述,鄱阳湖水利枢纽工程的建设对草鱼洄游的影响仅体现在枯水年成鱼出湖效率偏 低,对草鱼幼鱼洄游上溯的影响较小, 现行调度方案总体上能够满足草鱼洄游需求。

\section{4 结论}

本文通过草鱼过闸洄游能力实验探索了鄱阳湖鱼类不同洄游时期草鱼的偏好流速, 并分别采用二维和三 维水动力模型对水利枢纽建设后鄱阳湖人江水道和水利枢纽过鱼通道水力学特性进行数值模拟,分析了枢纽 建设对草鱼江湖洄游的影响。结果表明:

(1) 草鱼幼鱼人湖期间,湖口段适宜通过天数达到 $83.74 \%$ 以上; 枢纽工程处在过鱼高峰期仍能保持较高 的过闸效率;鱼道运行存在局部流速过大的现象,不满足上溯条件。

(2) 草鱼成鱼出湖期间,丰、平水年闸前水动力的变化对出湖行为影响较小, 仅枯水年的适宜出湖天数偏 低,但总体满足出湖要求。

(3) 在本研究选择的设计调度模式下, 水利枢纽建设运行后鄱阳湖整体水动力条件能够满足草鱼洄游需 求,而目前设计的鱼道水动力条件在不同时期均不能满足草鱼洄游需求。

\section{参考文献 (References) :}

[1] 张堂林, 李钟杰. 鄱阳湖鱼类资源及渔业利用. 湖泊科学, 2007, 19(4)：434-444.

[ 2 ] 曾泽国, 张笑辰, 刘观华, 金杰峰, 陈家宽, 金斌松. 鄱阳湖子湖“堑秋湖”渔业资源结构特征分析. 长江流域资源与环境, 2015,24(6)： 1021-1029.

[ 3 ] 张堂林, 李钟杰, 郭青松. 长江中下游四个湖泊鱼类与渔业研究. 水生生物学报, 2008, 32(2): 167-177.

[ 4 ］夏少霞, 于秀波, 刘宇, 贾亦飞, 张广帅. 鄱阳湖湿地现状问题与未来趋势. 长江流域资源与环境, 2016, 25(7): 1103-1111.

[ 5 ] 刘飞, 林鹏程, 黎明政, 高欣, 王春伶, 刘焕章. 长江流域鱼类资源现状与保护对策. 水生生物学报, 2020, 43(S1): 144-156.

[ 6 ] 葛刚, 纪伟涛, 刘成林, 熊舒, 吴志强. 鄱阳湖水利枢纽工程与湿地生态保护. 长江流域资源与环境, 2010, 19(6): 606-613.

[ 7 ] Lai G Y, Wang P, Li L. Possible impacts of the Poyang Lake (China) hydraulic project on lake hydrology and hydrodynamics. Hydrology Research, 2016, 47(S1): 187-205.

[ 8 ] Tsuboi J I, Endou S, Morita K. Habitat fragmentation by damming threatens coexistence of stream-dwelling charr and salmon in the Fuji River, Japan. Hydrobiologia, 2010, 650(1): 223-232.

[ 9 ] 何晓辉, 谈龙飞, 彭云釒, 方弟安, 徐东坡. 长江湖口段四大家鱼卵资源及其产卵场分布. 中国水产科学, 2021, 28(4)：420-430.

[10］胡茂林. 鄱阳湖湖口水位、水环境特征分析及其对鱼类群落与洄游的影响 [D ]. 南昌: 南昌大学, 2009.

[11] Duan X B, Liu S P, Huang M G, Qiu S L, Li Z H, Wang K, Chen D Q. Changes in abundance of larvae of the four domestic Chinese carps in the 
middle reach of the Yangtze River, China, before and after closing of the Three Gorges Dam. Environmental Biology of Fishes, 2009, 86( 1) : $13-22$.

[12] 万正义, 方春林, 邓水山, 付辉云, 胡成钥, 毛慧玲, 余静春, 王虹, 黄丹. 四大家鱼养殖模式与经济效益分析. 江西水产科技, 2015, (4) : $11-14$.

[13] 柏海霞, 彭期冬, 李棚, 任杰. 长江四大家鱼产卵场地形及其自然繁殖水动力条件研究综述. 中国水利水电科学研究院学报, 2014 , 12 (3) : 249-257.

［14］江西省鄱阳湖水利枢纽建设办公室. 为了“一湖清水”一一鄱阳湖水利枢纽工程介绍. 江西水利科技, 2013, 39(2): 83-91.

[15] 杜彦良, 周怀东, 毛战坡, 刘晓波. 鄱阳湖水利枢纽工程对水质环境影响研究. 中国水利水电科学研究院学报, 2011,9 (4): 249-256.

[16] 申宏伟. Delft3d 软件在水利工程中的数值模拟. 水利科技与经济, 2005, 11(7): 440-441, 448-448.

[17] 姚静, 张奇, 李云良, 李梦凡. 定常风对鄱阳湖水动力的影响. 湖泊科学, 2016, 28(1): 225-236.

[18] 毛喜, 脱友才, 安瑞冬, 李嘉, 易文敏. 结构变化对鱼道水力学特性的影响. 四川大学学报: 工程科学版, 2012, 44(3): 13-18.

[19］谭细畅，李新辉，陶江平，李捷，王超，罗建仁，赖子尼. 西江肇庆江段鱼类早期资源时空分布特征研究. 淡水渔业，2007，37(4)： $37-40$.

[20] 涂志英, 袁喜, 韩京成, 石小涛, 刘国勇, 刘德富, 黄应平. 鱼类游泳能力研究进展. 长江流域资源与环境, 2011, 20( S1): 59-65.

[21] 汤新武. 鱼类过闸的水动力影响机理及模拟 $[D]$. 宜昌: 三峡大学, 2015 .

[22] 白艳勤, 路波, 罗佳, 梁园园, 刘德富, 陈求稳, 石小涛. 草鱼、鲢和瓦氏黄颡鱼幼鱼感应流速的比较. 生态学杂志, 2013, 32(8)： 2085-2089

[23] 房敏, 蔡露, 高勇, 涂志英, 王从锋, 黄应平. 运动消耗对草鱼幼鱼游泳能力的影响. 长江流域资源与环境, 2014, 23(6) : 816-820.

[24] 曹平, 穆祥鹏, 白音包力臮, 王秀英, 陈云飞. 与鱼道水力设计相关的草鱼幼鱼游泳行为特性研究. 水利学报, 2017 , 48 (12) : 1456- 1464

[25] 龚丽, 吴一红, 白音包力臬, 穆祥鹏. 草鱼幼鱼游泳能力及游泳行为试验研究. 中国水利水电科学研究院学报, 2015, 13 ( 3 ) : 211-216.

[26] 赖锡军, 姜加虎, 黄群. 三峡工程蓄水对鄱阳湖水情的影响格局及作用机制分析. 水力发电学报, 2012, 31(6)：132-136, 148-148.

[27］郑守仁. 三峡工程 175 米试验性蓄水运行期的科学调度优化运行试验. 长江技术经济, 2019, 3(1)：5-10.

[28］胡茂林, 吴志强, 刘引兰. 鄱阳湖湖口水域四大家鱼幼鱼出现的时间过程. 长江流域资源与环境, 2011, 20(5)：534-539.

[29] Hu Q, Feng S, Guo H, Chen G Y, Jiang T. Interactions of the Yangtze river flow and hydrologic processes of the Poyang Lake, China. Journal of Hydrology, 2007, 347(1/2): 90-100.

[30］杨少荣, 黎明政, 朱其广, 王美荣, 刘焕章. 鄱阳湖鱼类群落结构及其时空动态. 长江流域资源与环境, 2015, 24(1): 54-64.

[31] Zhang Q, Ye X C, Werner A D, Li Y L, Yao J, Li X H, Xu C Y. An investigation of enhanced recessions in Poyang Lake: comparison of Yangtze River and local catchment impacts. Journal of Hydrology, 2014, 517: 425-434.

[32] 赖格英, 张志勇, 王鹏, 吴青, 潘思怡, 胡兴兴, 陈桃金. 拟建鄱阳湖水利枢纽工程对长江干流流量影响的模拟. 湖泊科学, 2017,29 (3) : 521-533

[33] 吴龙华. 长江三峡工程对鄱阳湖生态环境的影响研究. 水利学报, 2007, 38(S1) : 586-591.

[34] Wang R W, David L, Larinier M. Contribution of experimental fluid mechanics to the design of vertical slot fish passes. Knowledge and Management of Aquatic Ecosystems, 2010, 396(2): 1-21.

[35] 边永欢, 孙双科, 张国强, 郑铁刚, 吕强. 坚缝式鱼道 90 转弯段水力特性的数值模拟. 水生态学杂志, 2015, 36( 1): 53-59.

[36] 杨培思, 蔡德所, 莫崇勋. 基于 FLOW-3D 的坚缝式鱼道水力特性研究. 广西大学学报：自然科学版, 2018, 43(4)：1675-1683.

[37] Liao J C, Beal D N, Lauder G V, Triantafyllou M S. Fish exploiting vortices decrease muscle activity. Science, 2003, 302 (5650) : 1566-1569.

[38］陈凯麒，常仲农，曹晓红，葛怀凤. 我国鱼道的建设现状与展望. 水利学报, 2012, 43(2): 182-188，197-197.

[39］高柱, 戴会超, 郭卓敏, 谭均军. 隔板型式对坚㖓式鱼道水力特性的影响研究. 水利水电技术, 2014, 45(10): 37-41.

[40] 杜浩, 班璇, 张辉, 危起伟, 陈大庆. 天然河道中鱼类对水深、流速选择特性的初步观测一以长江江口至涴市段为例. 长江科学院院 报, 2010, 27(10): 70-74. 